\title{
Energy Storage System for Solar Thermal Air Conditioning Combined with Ejector Cooling System
}

\author{
Sarayooth Vaivudh \\ School of Renewable Energy Technology, Naresuan University, Phitsanulok 65000, Thailand
}

Received: December 02, 2014 / Accepted: December 31, 2014 / Published: February 28, 2015.

\begin{abstract}
A system of energy storage for solar thermal air conditioning combined with ejector cooling system for residential is determined in this paper. The purpose of this study is to design the energy storage system for heating the water in a storage tank to reach the required temperature for exchanging heat with the refrigerant of cooling system. The design from calculation of thermal energy storage system that proper with the solar flat plate collector area results are $70 \mathrm{~m}^{2}$, and the hot water temperature is over than $80{ }^{\circ} \mathrm{C}$. A cooling system is selected for refrigerant of $\mathrm{R} 141 \mathrm{~b}$ from the solar air conditioning system of $10.5 \mathrm{~kW}$, and the energy source is solar thermal energy from the collector that there is an efficiency of 0.46 approximately. This storage system for the electric solar cooling system can be reduced the problem of the intermittent of energy source with the constant generating temperature to run the cooling system continuously.
\end{abstract}

Key words: Energy storage system, solar thermal air conditioning, ejector cooling system.

\section{Introduction}

Global warming in present has been increased continuously due to warm the weather to high temperature that uncomfortable to the people in residents. The temperature in the residents is reduced to comfortable range by cooling from the refrigerants and air-conditions. So, the electricity energy is needed to use in cooling equipments that higher consumed comparing with the other appliances. The estimation of the IIR (International Institute of Refrigeration) in Paris was informed about $15 \%$ of electricity produced in the whole world that employed for refrigeration and air-conditioning systems and the electricity consumption of the whole household and commercial buildings was around $45 \%$ for the cooling [1]. The problem solving of the energy demand from the growing population and fast depleting reserves of fossil fuels was to develop and use of renewable energy resources such as solar energy for reducing the fossil fuels and electricity demand. Solar energy was a good

Corresponding author: Sarayooth Vaivudh, Ph.D., research field: renewable energy. E-mail: sarayooth_v@hotmail.com. agreement renewable energy source for the ejector refrigeration system. The heat from solar energy was used to be the input of the cooling system. An important device in the solar cooling system for increasing the refrigerant pressure without consuming mechanical energy was the ejector which their characteristics of simple and efficiency technology for using by thermal only, therefore the ejector can be used to replace the compressor in the air conditioner.

Moreover, the solar ejector cooling system in a recent study by using a proper refrigerant and single-glazed collector can obtain a better coefficient of performance COP (coefficient of performance). The solar collector needs to operate at a high temperature over than $80{ }^{\circ} \mathrm{C}$ [2]. Ejectors are suitable for solar cooling application due to simple design and low cost. The storage solar hot water is heated for running the system by the circulation pump to exchange heat of the ejector cooling system generator [3]. This paper expresses to design the solar hot water system using in ejector cooling system, according to the conventional solar ejector cooling system that is available for 
reducing the electric devices using in the system.

\section{Solar Energy for Cooling System}

The solar cooling system is typically consisted of three subsystems, a solar collector system, an ejector cooling system, and air-conditioning system. The major energy gains in the cooling system are the visible light from the sun due to the efficiency of the solar collector that define as the ratio of the useful heat output to the total incident of solar radiation. The collector is used to perform as the energy conversion system by absorbs solar energy to heat the working fluid in the collector and then stored in a thermal storage tank [4]. The thermal air condition system is run by the refrigerant that circulates through the entire cooling system of thermal air conditioning unit (air conditioning, A.C.) to exchange heat at the thermal storage tank as shown in Fig. 1.

The solar energy collected is carried from the circulated fluid directly to the hot water in a storage tank from which it can transfer heat to the refrigerant. In this research, the commercially double glazed surface flat plate collector was selected from the efficiency that experimentally determined according to the modified ANSI/ASHRAE 93-1836 Standard [6].

$$
\eta_{s c}=0.80-3.5 \frac{T_{i}-T_{a}}{I}
$$

where, $T_{i}$ and $T_{a}$ are collector inlet and ambient temperature, $I$ is the incident solar radiation, $\mathrm{W} / \mathrm{m}^{2}$.

The conventional solar collector efficiency was calculated by the heat transfer principle following the Eq. (2) [7]:

$$
\eta_{s c}=F_{R}(\tau \alpha)-F_{R} U_{L} \frac{T_{i}-T_{a}}{I}
$$

where, $F_{R}$ is the heat transfer factor of removal heat, $\tau$ and $\alpha$ are the solar incident ratio and absorption respectively, $U_{L}$ is the total heat loss coefficient of collector.

From the comparing between Eq. (1) and Eq. (2),

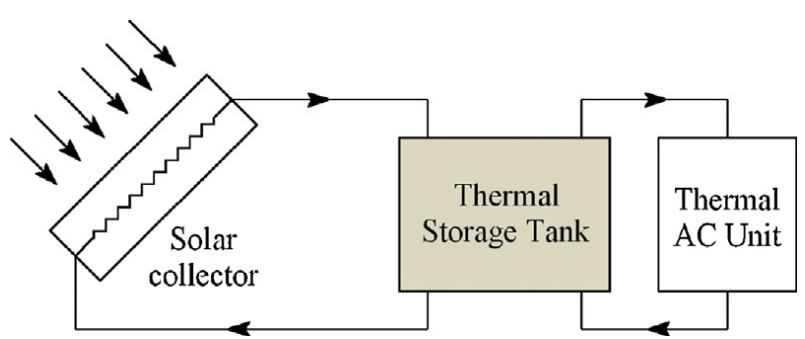

Fig. 1 Schematic of a solar cooling system [5].

then $F_{R}(\tau \alpha)$ and $F_{R} U_{L}$ are 0.8 and 3.5 respectively. These parameters are used for selection of solar collector by Humberto [8], a low cost, specially designed and high COP which the inlet temperature was higher than the generating temperature at around $10{ }^{\circ} \mathrm{C}$.

A performance testing result of the flat plate collector from Eq. (1) is evaluated the overall COP by following the Eq. (3) [6]:

$$
C O P_{0}=C O P_{E C S} \eta_{s c}
$$

where, $C O P_{0}$ is the overall system COP of the system, $C O P_{E C S}$ is the COP of the ejector cooling system.

\section{Solar Ejector Cooling System Performance}

Thermal energy from solar collector is used for driving the ejector cooling system and obtaining the generating temperature usually of higher than $70{ }^{\circ} \mathrm{C}$. Therefore the solar collector needs to operate system at temperature of water that higher than the generating temperature of around $10{ }^{\circ} \mathrm{C}$ which accords to the result of other works [8].

The ejector cooling is performed by the refrigerant and the thermodynamic cycle design. The selected refrigerant in this paper is $\mathrm{R} 141 \mathrm{~b}$ due to the high COP for a single stage ejector cooling system. In the solar ejector cooling system, the overall COP is reached as high as 0.22 and depends on the low operated evaporating temperature [6]. The ejector cross section of operation performance is shown in Fig. 2 [9].

In Fig. 2, the ejector is consisted of four main parts, a primary nozzle, a mixing chamber, a constant area throat and a subsonic diffuser and these main parts of the ejector are connected by fine screws. An ejector 


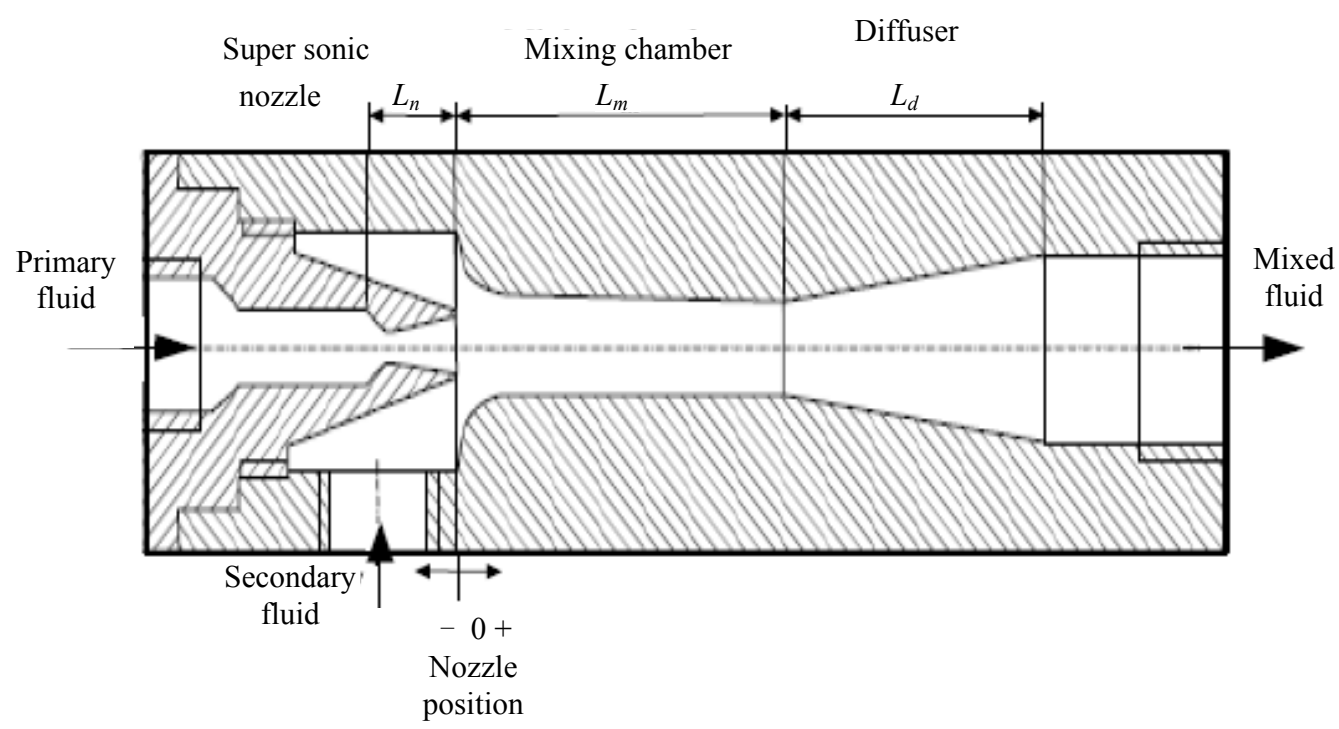

Fig. 2 Cross section diagram of the ejector with the fluid flow direction.

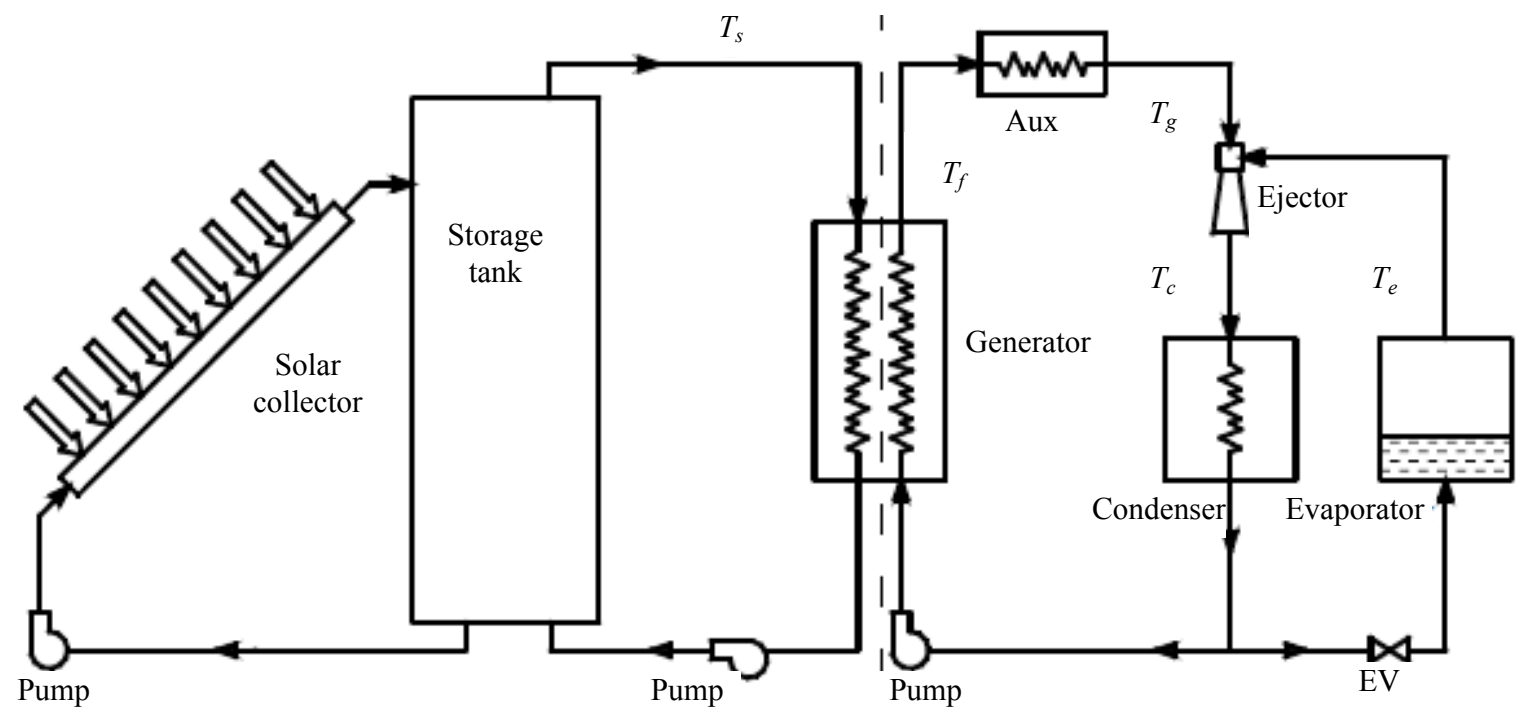

Fig. 3 Schematic diagram of solar ejector cooling system.

operation is designed by the entrainment ratio that defines by the ratio of the entrained secondary flow rate to the primary flow rate. The entrainment ratio is inversely proportional to the compression ratio as shown in the Eq. (4) [10]:

$$
\omega=\frac{\dot{m}_{e v}}{\dot{m}_{g}}
$$

where, $\dot{m}_{e v}$ is the entrained of evaporator flow, $\dot{m}_{g}$ is the generator flow.
The cycle process of the solar ejector cooling system is shown in the schematic diagram in order to express the structure of the system as shown in Fig. 3 [10].

The major components in the diagram are the solar collector, a hot water storage tank, an ejector, generator, condenser, an Aux (auxiliary heat), evaporator and cycle pump. In the generator, the collector pump circulates water between the collector and the storage tank. The hot water in the storage tank is carried to the generating refrigerant for vaporizing the refrigerant. When the heat provides by the storage is not sufficient, 
the auxiliary heat is an additional source to ensure that the ejector achieves the pressure and temperature condition. The high pressure primary refrigerant flow is generated and the low pressure refrigerant flow coming from the evaporator is induced to the ejector. Both of refrigerant vapor streams are mixed in the mixing chamber and induce to create the compression effect. The mixed stream is then discharged via the diffuser to the condenser and rejecting heat out by the cooling system. The refrigerant is flown through the expansion valve to the evaporator for absorbing heat at low temperature, and then the remaining liquid refrigerant is pressurized by the pump and vaporized in the generator by using heat from the solar collector.

\section{The Experimental Study on the Solar Ejector Cooling System}

The experimental study of the system using R141b was carried out under the condition of ambient temperature of $30{ }^{\circ} \mathrm{C}$ and a double glazed flat plate collector which performance parameters of $F_{R}(\tau \alpha)=$ 0.8 and $F_{R} U_{L}=3.5$. The solar radiation data were recorded by a pyranometer in a sample day hourly at the same time with the collector outlet temperature that was presented in Fig. 4.

The average of heat for the day for running the system was started at 10:00 until 15:00 that indicated from the temperature output of the collector of over 80 ${ }^{\circ} \mathrm{C}$. The suitable calculation flow rate of the water from the collector was around $0.1 \mathrm{~kg} / \mathrm{s}$ or $360 \mathrm{~L} / \mathrm{h}$ for the collector area of $70 \mathrm{~m}^{2}$. The power from the hot water in the storage tank was varied with the radiation and exchanged to the refrigerant with the efficiency of 0.46 approximately. In the case of storage principle, the heated water charged to the $2,880 \mathrm{~kg}$ in the $3 \mathrm{~m}^{3}$ water storage tank for one day, and discharged of $33.74 \mathrm{~kW}$ to the refrigerant in the generator, according to the system of Huang [6] for the cooling system capacity of $10.5 \mathrm{~kW}$.

The water temperature in the storage tank was increased with the solar radiation. A maximum of water temperature was $98{ }^{\circ} \mathrm{C}$ at noon suitable for running the system when the temperature was reached about $80^{\circ} \mathrm{C}$ and then transferred heat to the refrigerant in the generator. At low temperature of water at before 10:00 and after 14:00, the temperature was too low under the working $T_{g}$, due to low water temperature from the solar collector. A heat exchanger was used to exchange heat between the water and the refrigerant for running the system when the $T_{g}$ reached $70{ }^{\circ} \mathrm{C}$ or below the solar hot water of $10{ }^{\circ} \mathrm{C}$ [2]. The evaporating temperature, $T_{e}$ was varied with $T_{g}$ as shown from the measurement by a thermocouple in Fig. 5 .

From Fig. 5, $T_{e}$ decreased linearly with increasing $T_{g}$

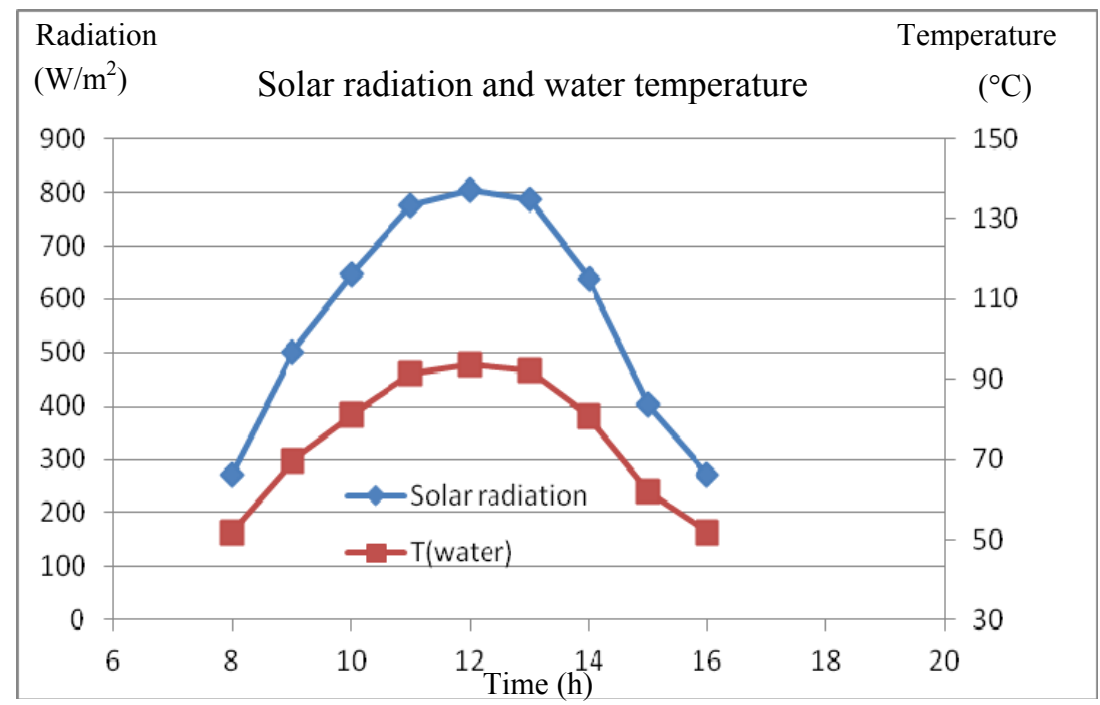

Fig. 4 Temperature of water at various times with radiation. 


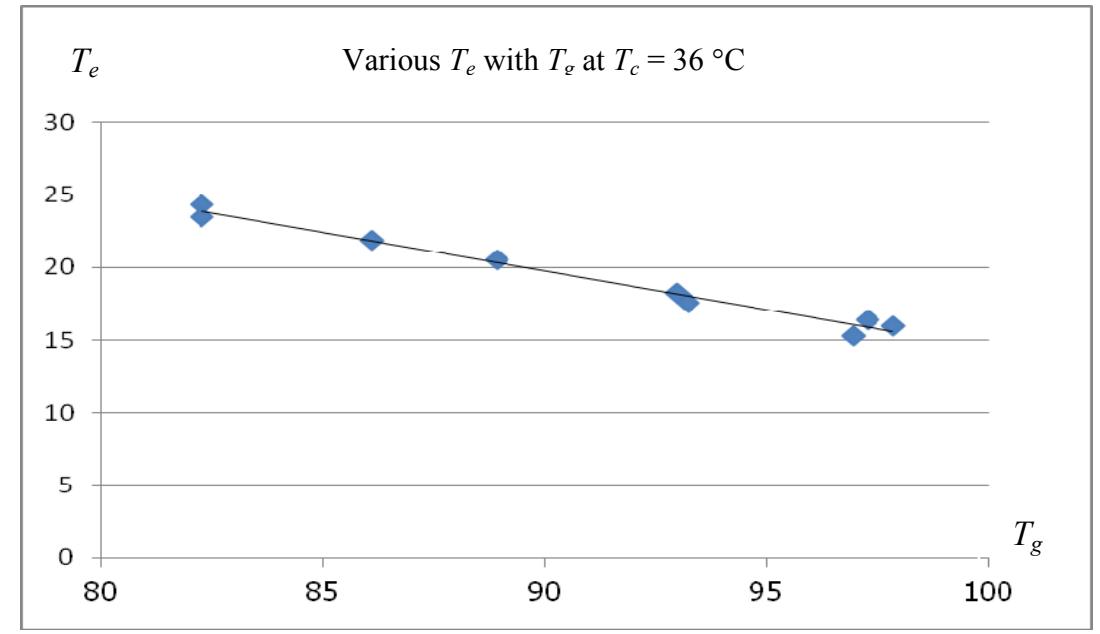

Fig. $5 T_{e}$ at condensing temperature of $36^{\circ} \mathrm{C}$.

in this case of the $T_{g}$ reached the performance temperature in the range of $80-98{ }^{\circ} \mathrm{C}, T_{e}$ was found in the range of $15-24{ }^{\circ} \mathrm{C}$. The solar collector efficiency in the range of this case was around 0.4 and the overall COP of the solar cooling system was reached of 0.2 approximately.

\section{Conclusions}

The solar ejector cooling system is affected by the hot water storage tank and the selected refrigerant, from the present study, R141b obtain a very high COP for a single stage ejector cooling system. From the experiment, the energy from the collector was changed with the solar radiation, and the water temperature was reached to $80^{\circ} \mathrm{C}$ for running the system when the solar radiation was impacted on a double glazed flat plate collector of around $700 \mathrm{~W} / \mathrm{m}^{2}$. A heat exchanger was exchanged heat between water in the collector loop and refrigerant in the cooling loop with the rate of 33.74 $\mathrm{kW}$. The cooling system was run when the storage hot water temperature was higher than generating temperature of $10{ }^{\circ} \mathrm{C}$ at cooling capacity of $10.5 \mathrm{~kW}$ from the example of solar cooling system that used to set up parameters for simulation with a solar storage system.

\section{Acknowledgments}

This research was supported by the Naresuan
University Research Fund. The author would like to thank for the accommodation of the university.

\section{References}

[1] Abduljateef, J. M., Sopian, K., Alghoul, M. A., and Sulaiman, M. Y. 2009. "Review on Solar-Driven Ejector Refrigeration Technologies.” Renewable and Sustainable Energy Reviews 13 (6-7): 1338-49.

[2] Huang, B. J., Petrenko, V. A., Samofatov, I. Y., and Shchtinina, N. A. 2001. "Collector Selection For Solar Ejector Cooling System.” Solar Energy 71 (4): 269-74.

[3] Huang, B. J., Yen, C. W., Wu, J. H., Liu, J. H., Hsu, H. Y., Petrenko, V. O., Chang, J. M., and Lu, C. W. 2010. "Optimal Control and Performance Test of Solar-Assisted Cooling System." Applied Thermal Engineering 30 (14-15): 2243-52.

[4] Huang, B. J., Ton, W. Z., Wu, C. C., Ko, H. W., Chang, H. S., Hsu, H. Y., Liu, J. H., Wu, J. H., and Yen, R. H. 2014. "Performance Test of Solar Assisted Ejector Cooling System." International Journal of Refrigeration 39 (Mar.): 172-85.

[5] Sarbu, L., and Sebarchievici, C. 2013. "Review of Solar Refrigeration and Cooling Systems." Energy and Buildings 67 (Dec.): 286-97.

[6] Huang, B. J., Chang, J. M., Petrenko, V. A., and Zhuk. K. B. 1998. "A Solar Ejector Cooling System Using Refrigerant R141b." Solar Energy 64 (4-6): 223-36.

[7] Guo, J., and Shen, H. G. 2009. "Modeling Solar-Driven Ejector Refrigeration System Offering Air Conditioning for Office Buildings." Energy and Buildings 41 (2): 175-81.

[8] Vidal, H., Colle, S., and Pereira, G. S. 2006. "Modeling 
and Hourly Simulation of a Solar Ejector Cooling System." Applied Thermal Engineering 26 (7): 663-72.

[9] Abdulateef, J. M., Murad, N. M., Alghout, M. A., Zaharim, A., and Sopian, K. 2011. "Experimental Study on Combined Solar-Assisted Ejector Absorption Refrigeration System." In Proceedings of the 4th WSEAS
International Conference on Energy and Development-Environment-Biomedicine, 162-6.

[10] Zhang, B., Lv, J. S., and Zuo, J. X. 2013. "Theoretical and Experimental Study on Solar Ejector Cooling System Using R236fa." International Journal of Low-Carbon Technologies (June): 1-5. 